Yüzüncü Yil Üniversitesi
Tarim Bilimleri Dergisi

Araştırma Makalesi (Research Article)

\title{
Bazı Aspir (Carthamus tinctorius L.) Çeşitlerinin Kök ve Sap Ekstraklarının Allelopatik ve Ototoksik Etkilerinin Belirlenmesi
}

\section{Engin Gökhan KULAN ${ }^{1}$, Nurgül ERGIN*², Mehmet Demir KAYA ${ }^{3}$}

${ }^{1,3}$ Eskişehir Osmangazi Üniversitesi, Ziraat Fakültesi, Tarla Bitkileri Bölümü, 26160, Eskişehir, Türkiye ${ }^{2}$ Bilecik Şeyh Edebali Üniversitesi, Ziraat ve Doğa Bilimleri Fakültesi, Tarla Bitkileri Bölümü, Bilecik, Türkiye ${ }^{1}$ https://orcid.org/0000-0002-7147-6896 ²https://orcid.org/0000-0003-3105-7504 3 https://orcid.org/0000-0002-4681-2464

*Sorumlu yazar e-posta: nurgulergin180@gmail.com

\section{Makale Bilgileri}

Geliș: 25.02 .2020

Kabul: 09.07.2020

Online Yayınlanma 31.12.2020

DOI: $10.29133 /$ yyutbd.694039

\section{Anahtar kelimeler}

Allelopati,

Buğday,

Çimlenme,

Carthamus tinctorius L.,

Fide gelişimi.
Öz: Bu çalışma, bazı aspir (Carthamus tinctorius L.) çeşitlerinin (Asol, Balcı, Linas ve Olas) kök ve sap kısımlarından elde edilen farklı dozlardaki (Kontrol, 12.5, 25.0 ve $50.0 \mathrm{~g} / \mathrm{L}$ ) solüsyonların arpa (Hordeum vulgare) ve buğdayın (Triticum aestivum) çimlenme ve fide gelişimi üzerine allelopatik etkileri ile aspir üzerine ototoksik etkilerini belirlemek amacıyla yürütülmüştür. Çimlenme yüzdesi (\%), çimlenme hızı (gün), kök ve sürgün uzunluğu $(\mathrm{cm})$, fide yaş ve kuru ağırlığı (g/bitki) ile kuru madde oranı (\%) incelenmiştir. Ayrıca hazırlanan solüsyonların elektriksel iletkenlik (EC) ve pH değerleri de belirlenmiştir. Araştırma sonuçlarına göre, sap solüsyonlarının EC değeri daha yüksek, pH değerleri ise daha düşük olduğu belirlenmiştir. Bitkilerin çimlenme yüzdesi ve hızında aspir çeşitlerine, bitki kısımlarına ve dozlara göre belirgin bir azalış veya artış elde edilmemiştir. Aspirde allelopatik ve ototoksik etkilerin sap kısmından kaynaklandığ tespit edilmiştir. Aspir çeşitlerinin allelopatik etkilerinin farklı olduğu ve Asol çeşidinin allelopatik ve ototoksik etkisinin daha az olduğu belirlenmiş̧tir. Sonuç olarak, aspir saplarının buğday ve arpa bitkilerinin fide gelişimi üzerine allelopatik etkisinin olduğu, Asol ve Linas çeşitlerinin ise diğer çeşitlere göre daha az zararlı etkisinin olduğu söylenebilir.

\section{Determination of Allelopathic and Autotoxic Effects of Root and Stem Extracts of Some Safflower (Carthamus tinctorius L.) Varieties}

Article Info
Received: 25.02 .2020
Accepted: 09.07 .2020
Online Published 31.12 .2020
DOI: 10.29133 yyutbd.694039

Keywords

Allelopathy, Wheat, Germination, Carthamus tinctorius L., Seedling growth.
Abstract: This study was carried out to determine the allelopathic effects of stem and root extracts with different doses (Control, 12.5, 25.0 and $50.0 \mathrm{~g} \mathrm{~L}^{-1}$ ) of some safflower (Carthamus tinctorius L.) cultivars (Asol, Balc1, Linas and Olas) on germination and seedling growth of barley (Hordeum vulgare) and wheat (Triticum aestivum) and autotoxic effects on safflower. Germination percentage (\%), mean germination time (day), root and shoot length $(\mathrm{cm})$, seedling fresh and dry weight (g plant ${ }^{-1}$ ) and dry matter (\%) were investigated. Electrical conductivity (EC) and $\mathrm{pH}$ values of the prepared solutions were also measured. The results showed that higher EC and lower $\mathrm{pH}$ values in stem solution were determined. There was no significant decrease or increase in germination percentage and speed in the plants with respect to safflower cultivars, plant parts and doses. Allelopathic and autotoxic effects of safflower were resulted from the stems, while no significant effect of root solution was found the investigated plants. It was determined that allelopathic effects of the safflower cultivars were different and the least toxicity was detected in Asol. It was concluded that safflower stems had allelopathic effect on seedling growth of wheat and barley plants, Asol and Linas had less hazardous effect than other cultivars. 


\section{Giriş}

Allelopati, bitkiler tarafindan salgilanan sekonder metabolitlerin diğer bitkilerin büyüme ve gelişmesini etkilemesi olarak tarif edilmektedir. Bu kimyasal maddeler diğer bitkileri doğrudan veya dolayl1, olumlu ya da olumsuz yönde etkileyebilmektedir (Rice, 1984; Willis, 2004). Bitkilerde allelopatik etkiler, ototoksisite (tür içi toksisite) ve heterotoksisite (türler arası toksisite) olmak üzere iki şekilde meydana gelmektedir. Bitkilerde bulunan en önemli allelokimyasallar, suda çözünebilen organik asitler, uzun zincirli yağ asitleri, fenoller, kumarinler, flavonoidler, tanenler, steroidler ve terpenler olarak sıralanmaktadır (Soltys ve ark., 2013). Bitkiler tarafindan savunma amaçlı kullanılan sekonder metabolitler de bitkinin kendisi için yüksek oranda fitotoksik etkiye sahip olabilmektedir (Gülsoy ve ark., 2008; Far ve Bagherzadeh, 2018). Bu kimyasallar, bitkilerde hücre bölünmesi ve büyümesi, fitohormonların dengesi, membran geçirgenliği ve bitki besin maddelerinin alımı, stomaların açılması, pigment sentezi, fotosentez, respirasyon, protein sentezi, yă ve organik asit metabolizmasında değişimler, azot fiksasyonu, spesifik enzim aktivitesi, ksilem dokularının mantarlaşması ve tıkanması ile suyun gövdede iletimini engelleme gibi çok farklı etkilerde bulunmaktadır (Li ve ark., 2010; Hussain ve Reigosa, 2011).

Hem dünyada hem de ülkemizde ekonomik yönden büyük öneme sahip soya fasulyesi (G. max), ayçiçeği (H. annuus), aspir (C. tinctorius L.), kanola (B. napus) ve susam (S. indicum) gibi yağ bitkileri, farklı familyalardan yabancı otların gelişimini engellemesinin (Işık ve ark., 2016; Yurttaş Kılınç, 2015) yanı sıra, kendisinden sonra gelen aynı tür ya da farklı türlerdeki kültür bitkilerinin de gelişimini olumlu ya da olumsuz yönde etkilemektedir (Shah ve ark., 2016). Aspir ekiminin yaygınlaşmamasındaki en önemli nedenin, özellikle ekim nöbetinde kendisinden sonra ekilen buğday ve arpa gibi bitkilerin verimini düşürmesi olarak görülmektedir. Aspir bitkisinin üretiminin yapıldığı alanlarda hasattan sonra tarlada kalan kök ve sap artıklarının buğday (T. aestivum cv. Tosunbey), ayçiçeği (H. annuus cv. Sanbro MR), nohut (C. arietinum cv. Gökçe) gibi kendinden sonra gelen bitki üzerinde allelopatik etkisinin olduğu tespit edilmiştir. Bu etkinin aspir sapında bulunan 2-Naphthalenemethanol, Lauryl alcohol ve Cylooctadiene, köklerde bulunan 1-Pentadecene, 2-Naphthalenemethanol ve Caryophyllene oxide gibi uçucu yağlardan kaynaklandığı tespit edilmiştir (Day, 2016). Ayrıca, aspir bitki artıklarının yabani arpa (H. spontaneum L.) tohumlarının çimlenmesini, kök ve sürgün büyümesini engellendiği (Miri, 2011), yabani hardal (Sinapis arvensis) tohumlarının çimlenmesi ile fide gelişimine olumsuz yönde etkilendiği (Modhej ve ark., 2013), kanolanın fide gelişimi ve erken gelişim dönemlerine allelopatik etkisinin olduğu (Bonamigo ve ark., 2013) da belirlenmiştir. Aspir bitkisinin allelopatik etki derecesi bitki organlarının allelokimyasal içeriği ve genotiplere göre farklılık göstermektedir. Motamedi ve ark. (2016) 40 aspir genotipinin allelopatik potansiyelini araştırdıkları çalışmada; genotiplerin turp (Raphanus sativus L.) bitkisinin kök ve sürgün uzunluğu, fide yaş ağırlığı ile çimlenme yüzdesini farklı oranlarda etkilediğini, ayrıca aspir köklerinin saplarına göre daha fazla ya da farklı allelokimyasallar içerebileceğini bildirmişlerdir. Bu çalışmada ise ülkemizde tescilli bazı aspir çeşitlerinin kök ve sap kısımlarından elde edilen solüsyonların buğday, arpa ve aspir tohumlarının çimlenme ve fide gelişimi üzerine allelopatik ve ototoksik etkileri araştırılmıştır.

\section{Materyal ve Yöntem}

Araştırmada; Asol, Balcı, Olas ve Linas aspir çeşitlerine ait bitkiler hasat zamanında, tarladan sökülmüş ve bitkiler tablaları uzaklaştırıldıktan sonra sap ve kök kısımları ayrılmıştır. Denemede kullanılan aspir bitkileri 2017 yılında Eskişehir Osmangazi Üniversitesi Ziraat Fakültesi araştırma ve deneme arazilerinde yetiştirilen bitkilerden elde edilmiştir. Sap ve kök kısımları birbirinden ayrıldıktan sonra kurutulmuş ve öğütülmüştür. Aspir köklerinin kurutmadan önce üzerindeki toprağın temizlenmesi amaciyla önce çeşme suyu ile yıkanmış, daha sonra saf su ile durulanarak kurutulmuştur. Ögütülmüş kök ve sap kısımlarından $12.5,25.0$ ve $50.0 \mathrm{~g}$ örnekler 1 litre saf su içerisine konularak iyice karıştırılmış ve iki gün boyunca $25 \pm 1^{\circ} \mathrm{C}$ 'ye ayarlanmış inkübatörde tamamen karanlık ortamda bekletilmiştir. İnkübasyon sonunda, su-ögütülmüş numune karışımı filtre kâğıdından süzülmüş ve farklı dozlarda solüsyonlar elde edilmiştir. Solüsyonların elektriksel iletkenlik (EC) (WTW 3.15i EC metre) ve pH değerleri (WTW 7310, pH metre) belirlenmiştir. Elde edilen solüsyonlar doğrudan çimlenme denemelerinde kullanılmış ve kullanılıncaya kadar $5^{\circ} \mathrm{C}$ sıcaklıkta inkübatörde bekletilmiştir. Kontrol olarak saf su kullanılmıştır. Araştırmada, Eskişehir yöresinde yaygın olarak tarımı yapılan Sönmez 
ekmeklik buğday çeşidi (T. aestivum), Aydanhanım iki sıralı arpa çeşidi (H. vulgare) ile Linas aspir çeşitlerine ait tohumlar kullanılmıştır.

Çimlenme denemeleri üç adet kurutma kâğ 1 dı arasında $20 \pm 1^{\circ} \mathrm{C}$ 'de, tamamen karanlık inkübatörde 10 gün yürütülmüştür. Enfeksiyonu önlemek amaciyla Thriam (\% 80) etken maddeli fungusit ( $3 \mathrm{~g} / \mathrm{L})$ kullanılmıştır. Deneme 4 tekerrürlü ve her tekerrürde 50 adet tohum olacak şekilde kurulmuştur. Tohumlar üç adet kurutma kâğıdı arasına yerleştirildikten sonra her bir kâğıt için $7 \mathrm{~mL}$ uygun solüsyondan eklenerek rulo haline getirilmiş ve buharlaşmayı engellemek için ağzı kilitli plastik torbalara konulmuştur. İki milimetre kökçük uzunluğuna sahip olanlar çimlenmiş kabul edilmiş ve çimlenen tohumlar her gün sayılmıştır (ISTA, 2003). Çimlenme hızını belirlemek amacıyla ortalama çimlenme süresi (OÇS) ISTA (2003)'e göre hesaplanmıştır.

$\mathrm{OÇS}=\Sigma(\mathrm{Dn}) / \Sigma \mathrm{n}$,

Formülde n: D gününde çimlenen tohum sayısını ve D: başlangıçtan itibaren çimlenme sayımının yapıldığı gün sayısını göstermektedir.

Kök ve sürgün uzunluğu ile fide yaş ve kuru ağırlığına ait ölçümler ise 10. günde yapılmıştır.

Üç faktörlü tesadüf parselleri deneme desenine göre kurulan deneme sonucunda elde edilen veriler, MSTAT-C paket programı kullanılarak değerlendirilmiştir. Uygulamalar arasındaki farkların önem düzeylerini belirleyebilmek amacıyla Duncan çoklu karşılaştırma testi uygulanmıştır (Düzgüneş ve ark., 1987).

\section{Bulgular ve Tartışma}

İncelenen dört aspir çeşidinin kök ve sap kısımları ile hazırlanan farklı dozdaki solüsyonların elektriksel iletkenlik (EC) ve pH değerleri Çizelge 1'de gösterilmiştir. Dozların artışına bağlı olarak solüsyonların EC değerleri artmış, $\mathrm{pH}$ değerleri ise değişmemiştir. Ancak kök solüsyonlarının $\mathrm{pH}$ değerlerinin, sap solüsyonlarından daha yüksek olduğu belirlenmiştir.

Çizelge 1. İncelenen aspir çeşitlerinin kök ve sap kısımları kullanılarak hazırlanan farklı dozlardaki solüsyonların $\mathrm{EC}$ ve $\mathrm{pH}$ değerleri

\begin{tabular}{|c|c|c|c|c|}
\hline \multirow{2}{*}{ Çeşit } & \multirow{2}{*}{ Bitki kısımları } & Doz (g/L) & $\mathrm{EC}(\mathrm{mS} / \mathrm{cm})$ & $\mathrm{pH}$ \\
\hline & & Saf su & 1.1 & 7.24 \\
\hline \multirow{6}{*}{ Asol } & \multirow{3}{*}{ Kök } & 12.5 & 458 & 6.51 \\
\hline & & 25.0 & 887 & 6.43 \\
\hline & & 50.0 & 1523 & 6.46 \\
\hline & \multirow{3}{*}{ Sap } & 12.5 & 1089 & 5.69 \\
\hline & & 25.0 & 2070 & 5.54 \\
\hline & & 50.0 & 3700 & 5.28 \\
\hline \multirow{6}{*}{ Balc1 } & \multirow{3}{*}{ Kök } & 12.5 & 538 & 6.44 \\
\hline & & 25.0 & 1010 & 6.39 \\
\hline & & 50.0 & 1790 & 6.47 \\
\hline & \multirow{3}{*}{ Sap } & 12.5 & 1197 & 5.58 \\
\hline & & 25.0 & 2240 & 5.54 \\
\hline & & 50.0 & 3930 & 5.72 \\
\hline \multirow{6}{*}{ Linas } & \multirow{3}{*}{ Kök } & 12.5 & 499 & 6.55 \\
\hline & & 25.0 & 769 & 6.53 \\
\hline & & 50.0 & 1290 & 6.57 \\
\hline & \multirow{3}{*}{ Sap } & 12.5 & 1042 & 5.61 \\
\hline & & 25.0 & 1905 & 5.48 \\
\hline & & 50.0 & 3705 & 5.75 \\
\hline \multirow{6}{*}{ Olas } & \multirow{3}{*}{ Kök } & 12.5 & 480 & 6.59 \\
\hline & & 25.0 & 718 & 6.69 \\
\hline & & 50.0 & 1276 & 6.64 \\
\hline & \multirow{3}{*}{ Sap } & 12.5 & 923 & 5.46 \\
\hline & & 25.0 & 1756 & 5.53 \\
\hline & & 50.0 & 3320 & 5.18 \\
\hline
\end{tabular}


Aspir çeşitleri, bitki kısımları ve dozlarına göre arpanın çimlenme yüzdesi ve hızı incelendiğinde, çeşitler arasında önemli bir farklılığın olmadığı, bitki kısımları ve dozları arasında istatistiksel farklılıklar belirlenmesine rağmen belirgin bir artış veya azalış eğiliminin olmadığı görülmektedir (Çizelge 2). Bununla birlikte, arpanın kök uzunluğu, sürgün uzunluğu, fide yaş ağırlığı aspir sapından elde edilen solüsyonda daha düşük elde edilirken, fide kuru ağırlı̆̆ 1 ve kuru madde oranının daha yüksek olduğu belirlenmiştir. Artan dozlar arpanın kök uzunluğunu kısaltmıştır. En uzun kök, saf su uygulanan kontrol dozunda $10.62 \mathrm{~cm}$ olarak elde edilirken, en düşük $50 \mathrm{~g} / \mathrm{L}$ solüsyon dozunda $8.62 \mathrm{~cm}$ olarak ölçülmüsşür. Balcı ve Olas çeşitlerinden hazırlanan solüsyonlarda, arpanın kök uzunluğu azalmıştır. Benzer bulgular Motamedi ve ark. (2016) tarafından hem laboratuvar hem de saksı çalışmalarında belirlenmiş olup, aspir genotiplerinin farklı allelopatik etkilere sahip olduğu ve incelenen aspir genotipleri arasında Mısır ve Khorasan çeşitlerinin Avusturalya ve Kerman çeşitlerine göre fide gelişimini daha fazla engellediğini bildirmişlerdir. Arpanın sürgün uzunluğu da artan solüsyon dozlarından olumsuz etkilenmiş, en uzun sürgün $17.05 \mathrm{~cm}$ ile $12.5 \mathrm{~g} / \mathrm{L}$ dozunda, en düşük değer ise $15.19 \mathrm{~cm}$ ile $50 \mathrm{~g} / \mathrm{L}$ dozunda ölçülmüştür.

Çizelge 2. Aspirde farklı bitki kısımları, çeşit ve dozlara göre hazırlanan solüsyonların arpanın çimlenme ve fide gelişimine etkileri

\begin{tabular}{cccccccc}
\hline Faktör & $\begin{array}{c}\text { Çimlenme } \\
(\%)\end{array}$ & $\begin{array}{c}\text { OÇS } \\
(\text { gün })\end{array}$ & $\begin{array}{c}\text { Kök uz. } \\
(\mathrm{cm})\end{array}$ & $\begin{array}{c}\text { Sürgün uz. } \\
(\mathrm{cm})\end{array}$ & $\begin{array}{c}\text { Yaş ağ. } \\
(\mathrm{g} / \mathrm{bitki})\end{array}$ & $\begin{array}{c}\text { Kuru ağ. } \\
(\mathrm{g} / \mathrm{b} \text { itki })\end{array}$ & $\begin{array}{c}\text { Kuru madde } \\
(\%)\end{array}$ \\
\hline Bitki kısımları & & & & & & & \\
\hline Kök & $99.1^{\mathrm{a}}$ & $2.01^{\mathrm{b}}$ & $10.92^{\mathrm{a}}$ & $17.64^{\mathrm{a}}$ & $1.216^{\mathrm{a}}$ & $0.153^{\mathrm{b}}$ & $12.58^{\mathrm{b} *}$ \\
Sap & $98.4^{\mathrm{b}}$ & $2.05^{\mathrm{a}}$ & $7.63^{\mathrm{b}}$ & $15.29^{\mathrm{b}}$ & $1.101^{\mathrm{b}}$ & $0.162^{\mathrm{a}}$ & $14.81^{\mathrm{a}}$ \\
\hline Çeşit & & & & & & & \\
\hline Asol & 99.1 & 2.03 & $10.16^{\mathrm{a}}$ & 16.56 & 1.178 & 0.158 & 13.46 \\
Balc1 & 98.6 & 2.04 & $8.47^{\mathrm{b}}$ & 16.26 & 1.155 & 0.158 & 13.87 \\
Linas & 98.8 & 2.03 & $9.82^{\mathrm{a}}$ & 16.63 & 1.151 & 0.158 & 13.83 \\
Olas & 98.6 & 2.02 & $8.65^{\mathrm{b}}$ & 16.39 & 1.151 & 0.156 & 13.64 \\
\hline Doz (g/L) & & & & & & & \\
\hline Kontrol & $99.0^{\mathrm{a}}$ & $2.02^{\mathrm{b}}$ & $10.60^{\mathrm{a}}$ & $16.58^{\mathrm{b}}$ & $1.180^{\mathrm{ab}}$ & 0.160 & $13.56^{\mathrm{b}}$ \\
12.5 & $99.1^{\mathrm{a}}$ & $2.02^{\mathrm{b}}$ & $8.69^{\mathrm{b}}$ & $17.05^{\mathrm{a}}$ & $1.121^{\mathrm{b}}$ & 0.152 & $13.64^{\mathrm{b}}$ \\
25.0 & $99.1^{\mathrm{a}}$ & $2.03^{\mathrm{b}}$ & $9.18^{\mathrm{b}}$ & $17.03^{\mathrm{a}}$ & $1.207^{\mathrm{a}}$ & 0.158 & $13.11^{\mathrm{b}}$ \\
50.0 & $97.9^{\mathrm{b}}$ & $2.06^{\mathrm{a}}$ & $8.62^{\mathrm{b}}$ & $15.19^{\mathrm{c}}$ & $1.126^{\mathrm{b}}$ & 0.159 & $14.48^{\mathrm{a}}$ \\
\hline
\end{tabular}

*: Harfler \%5 düzeyinde önemli.

Arpanın kök ve sürgün uzunluğu üzerine aspir çeşit $\times$ doz ve bitki kısımları $\times$ doz interaksiyonları Şekil l'de gösterilmiştir. Kök uzunluğu üzerine Asol ve Linas çeşitlerinin önemli etkisi görülmezken, Balcı ve Olas çeşitlerinin artan dozları, arpanın kök uzunluğunu olumsuz etkilemiştir. Tüm çeşitlerin $50 \mathrm{~g} / \mathrm{L}$ dozu, arpanın sürgün gelişimini engellemiştir. Bitki kısımları $\times$ doz interaksiyonları incelendiğinde, aspir saplarından elde edilen solüsyonların arpa kök uzunluğunu önemli derecede azalttığı görülmektedir. Sürgün uzunluğu ise sap solüsyonlarında daha kısa elde edilse de, en şiddetli azalışın $50 \mathrm{~g} / \mathrm{L}$ dozunda olduğu belirlenmiştir. 
Kök uzunluğu (cm)
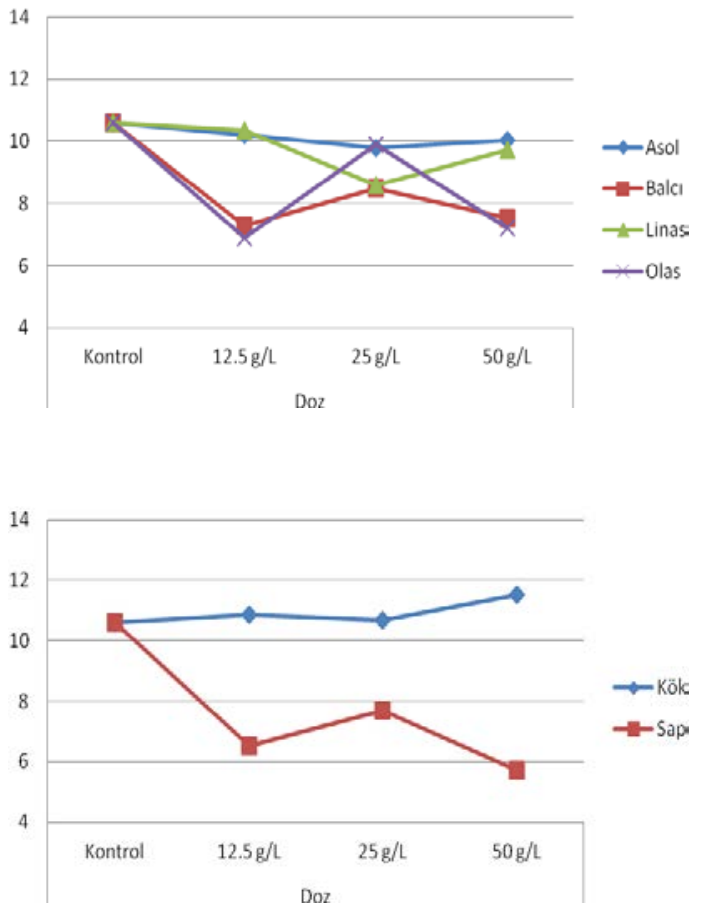

Sürgün uzunluğu $(\mathrm{cm})$
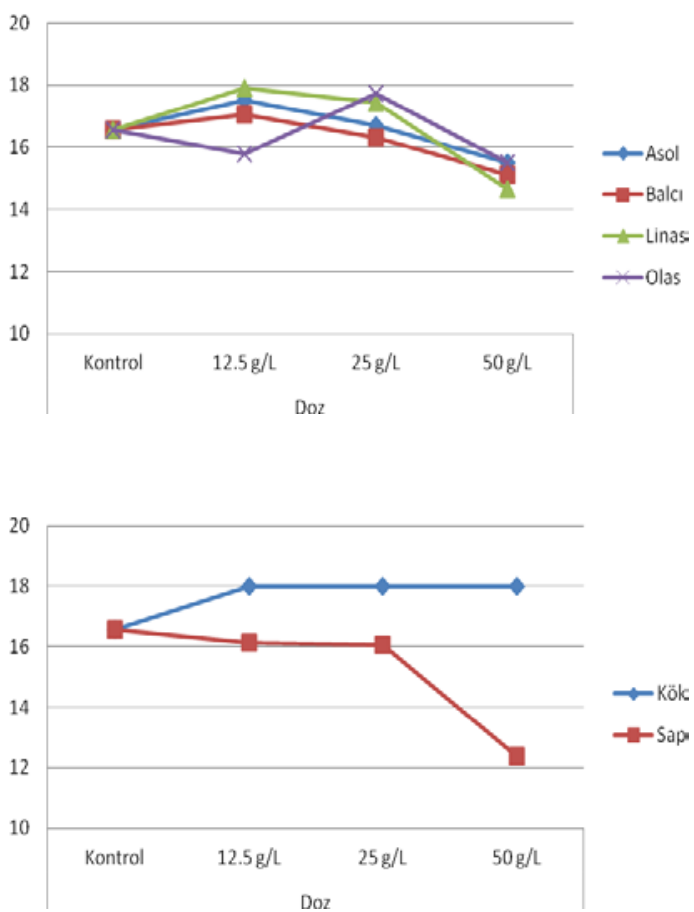

Şekil 1. Arpanın kök ve sürgün uzunluğu üzerine çeşit $\times$ doz ve bitki kısımları $\times$ doz interaksiyonları.

Buğdayın çimlenme ve fide gelişimi üzerine aspir solüsyonları ve dozlarının etkileri Çizelge 3'de özetlenmiştir. Çimlenme yüzdesi artan dozlara bağl1 olarak \% 100'den \% 97.2'ye düşmüştür. Ayrıca, sap solüsyonlarında daha düşük çimlenme (\%98.4) ve daha uzun çimlenme süresi (2.18 gün) elde edilmiştir. Motemadi ve ark. (2016) farklı aspir genotiplerinin kök ve saplarıyla hazırladığ solüsyonlar arasında, kök solüsyonlarının, sap solüsyonlarına göre bitki gelişimini daha fazla engellediğini belirtmişlerdir. Day (2016) aspir saplarından elde edilen özütlerde buğday kök uzunluğunun daha kısa olduğunu bildirmiştir. Bitki kısımlarının allelopatik etkileri arasındaki bu farklılık, bu kısımlarda farklı oranlarda ve çeşitlere göre farklı allelokimyasallar bulunmasından kaynaklanabilmektedir (Miri, 2011). Buğdayda kök uzunluğu üzerinde aspir çeşitleri arasında istatistiki anlamda önemli farkl11ıklar bulunmuştur. En düşük kök uzunluğu değerleri Balcı $(6.91 \mathrm{~cm})$ çeşidinde belirlenmiştir. Saf su uygulanan kontrol dozunda en yüksek kök uzunluğu değeri $(12.38 \mathrm{~cm})$ elde edilirken, $25 \mathrm{~g} / \mathrm{L}$ ve $50 \mathrm{~g} / \mathrm{L}$ dozunda hazırlanan solüsyonlar en düşük kök uzunluğu $(6.38 \mathrm{~cm}$ ve 6.58 $\mathrm{cm}$ ) değerlerini vermiştir. Miri (2011) çeşitli kültür bitkilerinin buğdayın çimlenmesi ile kök ve sürgün uzunluğuna fitotoksik etkide bulunduğunu; maş fasulyesi (Vigna radiata), şeker pancarı (Beta vulgaris sacchariferae), bakla (Vicia faba) ve aspir (C. tinctorius L.) yaprak ekstraklarının, buğdayın kök uzunluğu \%40 oranında azalttığı bildirmiştir. Ancak, çalışmamızda artan dozlar buğdayın sürgün uzunluğun arttırmıştır. En uzun sürgün $12.01 \mathrm{~cm}$ ile $12.5 \mathrm{~g} / \mathrm{L}$ dozundan elde edilirken, en düşük değer $6.20 \mathrm{~cm}$ ile saf su uygulanan kontrol dozundan elde edilmiştir. Kontrol ile kıyaslandığında, artan solüsyon dozları fide yaş ağırlığını azaltmış, en düşük değer $0.711 \mathrm{~g} / \mathrm{bitki}$ ile $50.0 \mathrm{~g} / \mathrm{L}$ dozunda elde edilmiştir. Ayrıca, aspir sapından elde edilen solüsyon, kök solüsyonuna göre, buğdayın fide yaş ağırlığında daha fazla azalmaya neden olmuştur. Fide kuru ağırlı̆̆ında ise istatistiksel olarak önemli farklılıklar belirlenmiş olmasına rağmen, belirgin bir atış veya azalış tespit edilmemiştir (Çizelge 3). 
Çizelge 3. Aspirde farklı bitki kısımları, çeşit ve dozlara göre hazırlanan solüsyonların buğdayın çimlenme ve fide gelişimine etkileri

\begin{tabular}{|c|c|c|c|c|c|c|c|}
\hline Faktör & $\begin{array}{l}\text { Çimlenme } \\
(\%)\end{array}$ & $\begin{array}{l}\text { OÇS } \\
\text { (gün) }\end{array}$ & $\begin{array}{c}\text { Kök uz. } \\
\text { (cm) }\end{array}$ & $\begin{array}{l}\text { Sürgün uz. } \\
\text { (cm) }\end{array}$ & $\begin{array}{l}\text { Yaş ağ. } \\
\text { (g/bitki) }\end{array}$ & $\begin{array}{l}\text { Kuru ağ. } \\
\text { (g/bitki) }\end{array}$ & $\begin{array}{c}\text { Kuru madde } \\
(\%)\end{array}$ \\
\hline \multicolumn{8}{|c|}{ Bitki kısımları } \\
\hline Kök & $99.1^{\mathrm{a}}$ & $2.02^{\mathrm{a}}$ & $10.08^{\mathrm{a}}$ & $11.02^{\mathrm{a}}$ & $0.854^{\mathrm{a}}$ & $0.151^{\mathrm{a}}$ & $17.71^{\mathrm{b} *}$ \\
\hline Sap & $98.3^{\mathrm{b}}$ & $2.18^{\mathrm{b}}$ & $6.26^{\mathrm{b}}$ & $8.07^{b}$ & $0.738^{\mathrm{b}}$ & $0.158^{\mathrm{b}}$ & $22.14^{\mathrm{a}}$ \\
\hline \multicolumn{8}{|l|}{ Çeşit } \\
\hline Asol & 98.8 & $2.07^{c}$ & $9.09^{a}$ & $9.65^{a}$ & 0.800 & $0.155^{\mathrm{ab}}$ & $19.72^{\mathrm{bc}}$ \\
\hline Balc1 & 98.6 & $2.12^{\mathrm{b}}$ & $6.91^{\mathrm{c}}$ & $9.77^{\mathrm{a}}$ & 0.788 & $0.161^{\mathrm{a}^{*}}$ & $21.01^{\mathrm{a}}$ \\
\hline Linas & 98.9 & $2.05^{c}$ & $9.08^{\mathrm{a}}$ & $9.68^{\mathrm{a}}$ & 0.802 & $0.150^{\mathrm{b}}$ & $18.99^{\mathrm{c}}$ \\
\hline Olas & 98.5 & $2.16^{\mathrm{a}}$ & $7.61^{\mathrm{b}}$ & $9.07^{b}$ & 0.793 & $0.152^{b}$ & $19.97^{\mathrm{b}}$ \\
\hline \multicolumn{8}{|l|}{ Doz (g/L) } \\
\hline Kontrol & $100.0^{\mathrm{a}}$ & $2.00^{\mathrm{d}}$ & $12.38^{\mathrm{a}}$ & $6.20^{\mathrm{d}}$ & $0.892^{\mathrm{a}}$ & $0.148^{\mathrm{c}}$ & $16.41^{\mathrm{d}}$ \\
\hline 12.5 & $99.2^{b}$ & $2.03^{c}$ & $7.36^{\mathrm{b}}$ & $12.01^{\mathrm{a}}$ & $0.787^{b}$ & $0.154^{\mathrm{b}}$ & $19.77^{c}$ \\
\hline 25.0 & $98.4^{\mathrm{c}}$ & $2.11^{\mathrm{b}}$ & $6.38^{c}$ & $10.71^{\mathrm{b}}$ & $0.793^{\mathrm{b}}$ & $0.163^{\mathrm{a}}$ & $20.87^{b}$ \\
\hline 50.0 & $97.2^{\mathrm{d}}$ & $2.26^{\mathrm{a}}$ & $6.58^{c}$ & $9.25^{c}$ & $0.711^{\mathrm{c}}$ & $0.153^{b}$ & $22.65^{\mathrm{a}}$ \\
\hline
\end{tabular}

*: Harfler \%5 düzeyinde önemli.

Buğdayda kök ve sürgün uzunluğuna çeşit $\times$ doz interaksiyonunun etkisi istatistiki olarak önemli bulunmuştur. En uzun kök kontrol dozunda belirlenirken, artan dozlar kök uzunluğunun kısalmasına neden olmuştur (Şekil 2). En düşük kök uzunluğu değer Balcı çeşidinin $12.5 \mathrm{~g} / \mathrm{L}$ dozundan elde edilmiştir. Artan dozlar aspir bitkisinin sürgün uzunluğunu arttırmış ve en uzun sürgün Linas çeşidinin $12.5 \mathrm{~g} / \mathrm{L}$ dozunda belirlenmiştir. Bitki kısımları $\times$ doz interaksiyonunda ise buğday kök uzunluğu artan dozlarla azalmış ve saplardan elde edilen solüsyonlarda daha kısa kök elde edilmiştir. Sürgün uzunluğu ise kök solüsyonlarında artış, sap solüsyonlarında ise $50 \mathrm{~g} / \mathrm{L}$ dozunda azalış göstermiştir.
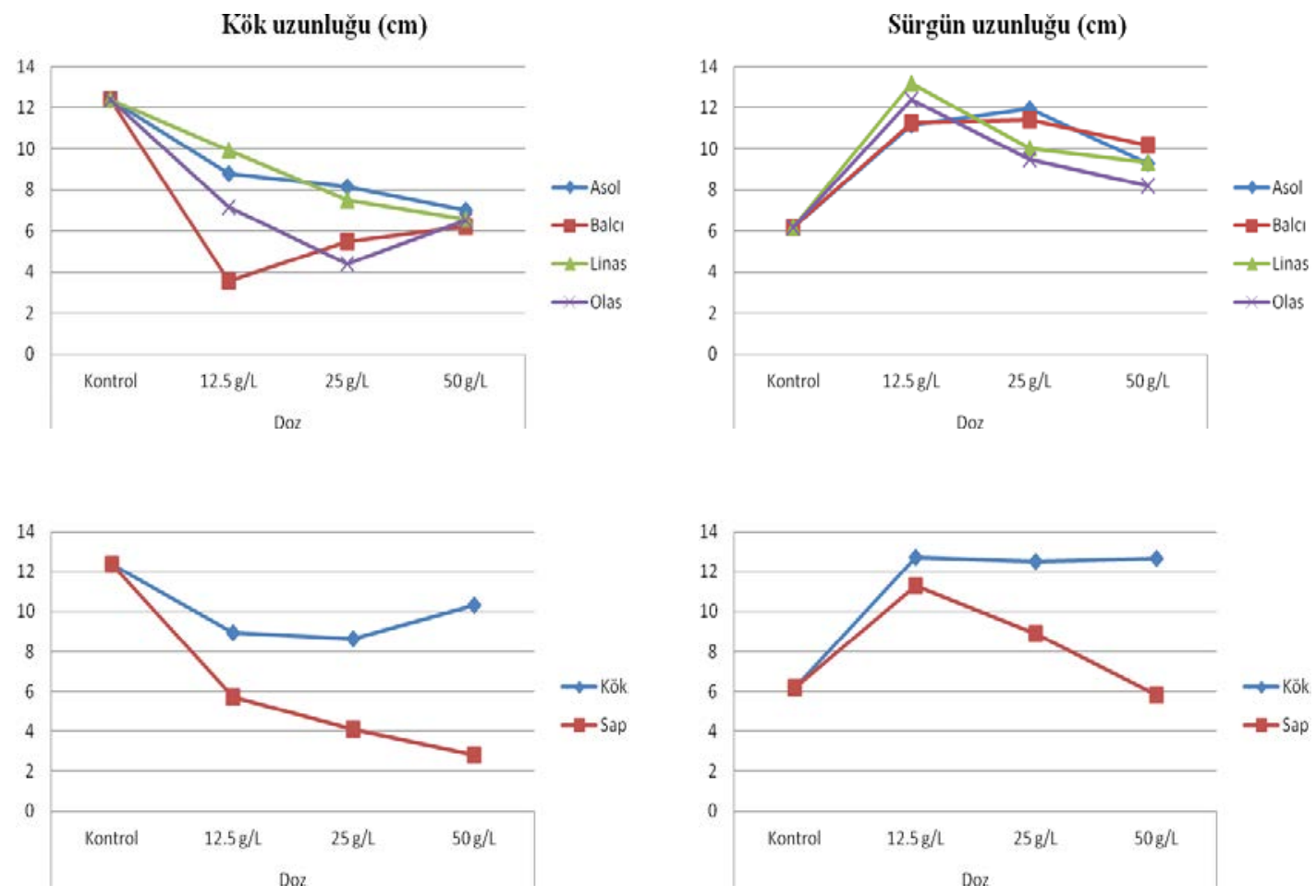

Şekil 2. Buğdayın kök ve sürgün uzunluğu üzerine çeşit $\times$ doz ve bitki kısımları $\times$ doz interaksiyonları. 
Aspir tohumlarının çimlenme yüzdesine dozların etkisi önemli bulunmuş ve dozlara göre çimlenme yüzdesi \% 98.3-\% 99.6 arasında belirlenmiştir. Aspir saplarından hazırlanan solüsyon, aspirin çimlenme süresini uzatmış, kök ve sürgün uzunluğunu engellemiş ve daha düşük fide yaş ağırlığı elde edilmiştir. Aspir çeşitlerinin de ototoksik etkilerinin farklı olduğu belirlenmiştir. Balcı ve Olas çeşitlerinin bitki solüsyonları, Asol ve Linas çeşitlerinin bitki solüsyonlarına göre kök uzunluğunu daha fazla kısaltmıştır. Asol çeşidinde en yüksek kök $(3.63 \mathrm{~cm})$ ve sürgün uzunluğu $(5.18 \mathrm{~cm})$ elde edilmiştir. Artan solüsyon dozları aspir fidelerinin kök uzunluğunu $3.58 \mathrm{~cm}$ 'den $2.49 \mathrm{~cm}$ 'ye düşürmüştür. Sürgün uzunluğu da artan dozlardan olumsuz etkilenmiş ve $50 \mathrm{~g} / \mathrm{L}$ dozunda $4.09 \mathrm{~cm}$ ile en kısa sürgün elde edilmiştir. Aspir fidelerinin kuru madde oranı sap solüsyonlarında \% 11.21, Olas çeşidinde \% 11.45 ve 50 g/L dozunda \% 11.89 ile en yüksek elde edilmiştir (Çizelge 4).

Çizelge 4. Aspirde farklı bitki kısımları, çeşit ve dozlara göre hazırlanan solüsyonların aspirin çimlenme ve fide gelişimine etkileri

\begin{tabular}{|c|c|c|c|c|c|c|c|}
\hline Faktör & $\begin{array}{c}\text { Çimlenme } \\
(\%)\end{array}$ & $\begin{array}{l}\text { OÇS } \\
\text { (gün) }\end{array}$ & $\begin{array}{c}\text { Kök uz. } \\
\text { (cm) }\end{array}$ & $\begin{array}{l}\text { Sürgün uz. } \\
\quad(\mathrm{cm})\end{array}$ & $\begin{array}{l}\text { Yaş ağ. } \\
\text { (g/bitki) }\end{array}$ & $\begin{array}{l}\text { Kuru ağ. } \\
\text { (g/bitki) }\end{array}$ & $\begin{array}{c}\text { Kuru } \\
\text { madde } \\
(\%)\end{array}$ \\
\hline \multicolumn{8}{|c|}{ Bitki kısımları } \\
\hline Kök & 98.9 & $1.80^{\mathrm{a}}$ & $3.88^{\mathrm{a}}$ & $5.53^{\mathrm{a}}$ & $1.379^{\mathrm{a}}$ & 0.128 & $9.31^{\mathrm{b} *}$ \\
\hline Sap & 98.7 & $1.85^{\mathrm{b}}$ & $2.50^{\mathrm{b}}$ & $4.46^{\mathrm{b}}$ & $1.319^{\mathrm{b}}$ & 0.127 & $11.21^{\mathrm{a}}$ \\
\hline \multicolumn{8}{|l|}{ Çeşit } \\
\hline Asol & 98.7 & $1.85^{\mathrm{a}}$ & $3.63^{a}$ & $5.18^{\mathrm{a}}$ & $1.296^{\mathrm{b}}$ & 0.130 & $10.14^{\mathrm{b}^{*}}$ \\
\hline Balc1 & 98.7 & $1.85^{\mathrm{a}}$ & $2.80^{\mathrm{b}}$ & $4.95^{\mathrm{ab}}$ & $1.236^{\mathrm{b}}$ & 0.129 & $10.63^{b}$ \\
\hline Linas & 99.1 & $1.81^{\mathrm{ab}}$ & $3.52^{\mathrm{a}}$ & $5.06^{\mathrm{ab}}$ & $1.619^{\mathrm{a}}$ & 0.127 & $8.82^{\mathrm{c}}$ \\
\hline Olas & 98.6 & $1.78^{\mathrm{b}}$ & $2.83^{\mathrm{b}}$ & $4.79^{\mathrm{b}}$ & $1.245^{\mathrm{b}}$ & 0.124 & $11.45^{\mathrm{a}}$ \\
\hline \multicolumn{8}{|l|}{ Doz (g/L) } \\
\hline Kontrol & $98.5^{\mathrm{b}}$ & $1.86^{\mathrm{b}}$ & $3.58^{\mathrm{a}}$ & $5.10^{\mathrm{b}}$ & $1.252^{\mathrm{d}}$ & $0.122^{b}$ & $9.67^{\mathrm{b}}$ \\
\hline 12.5 & $99.6^{\mathrm{a}}$ & $1.72^{\mathrm{d}}$ & $3.25^{b}$ & $5.51^{\mathrm{a}}$ & $1.390^{\mathrm{b}}$ & $0.132^{\mathrm{a}}$ & $9.61^{b}$ \\
\hline 25.0 & $98.8^{\mathrm{ab}}$ & $1.81^{\mathrm{c}}$ & $3.45^{\mathrm{ab}}$ & $5.29^{\mathrm{ab}}$ & $1.309^{c}$ & $0.127^{\mathrm{ab}}$ & $9.88^{\mathrm{b}}$ \\
\hline 50.0 & $98.3^{\mathrm{b}}$ & $1.90^{\mathrm{a}}$ & $2.49^{c}$ & $4.09^{c}$ & $1.443^{\mathrm{a}}$ & $0.129^{\mathrm{ab}}$ & $11.89^{\mathrm{a}}$ \\
\hline
\end{tabular}

*: Harfler \%5 düzeyinde önemli.

Aspir kök ve sürgün uzunluğuna çeşit $\times$ doz interaksiyonu istatistiki olarak önemli bulunmuştur (Şekil 3). En uzun kök Asol çeşidi ile $25 \mathrm{~g} / \mathrm{L}$ dozunda hazırlanan solüsyon uygulamasından elde edilirken, en kısa kök uzunluğu Olas çeşidi bitki parçalarıyla $50 \mathrm{~g} / \mathrm{L}$ dozunda hazırlanan solüsyon uygulamasından elde edilmiştir. Sürgün uzunluğunda ise, Olas çeşidi ile $12.5 \mathrm{~g} / \mathrm{L}$ dozunda hazırlanan solüsyon uygulaması en yüksek değeri verirken, en düşük değere Olas çeşidi ile $50 \mathrm{~g} / \mathrm{L}$ dozunda hazırlanan solüsyon uygulamasında ulaşılmıştır. Bitki kısımları $\times$ doz interaksiyonu incelendiğinde, aspir bitkisinin kök uzunluğunu artan dozlarda sap solüsyonları önemli şekilde azalttığı görülmektedir. Benzer şekilde aspirin sürgün uzunluğunda da belirlenmiş ve sap solüsyonunun artan dozları, özellikle $50 \mathrm{~g} / \mathrm{L}$ dozu, sürgün uzunluğunun kısalmasına neden olmuştur. 
Kök uzunluğu $(\mathrm{cm})$
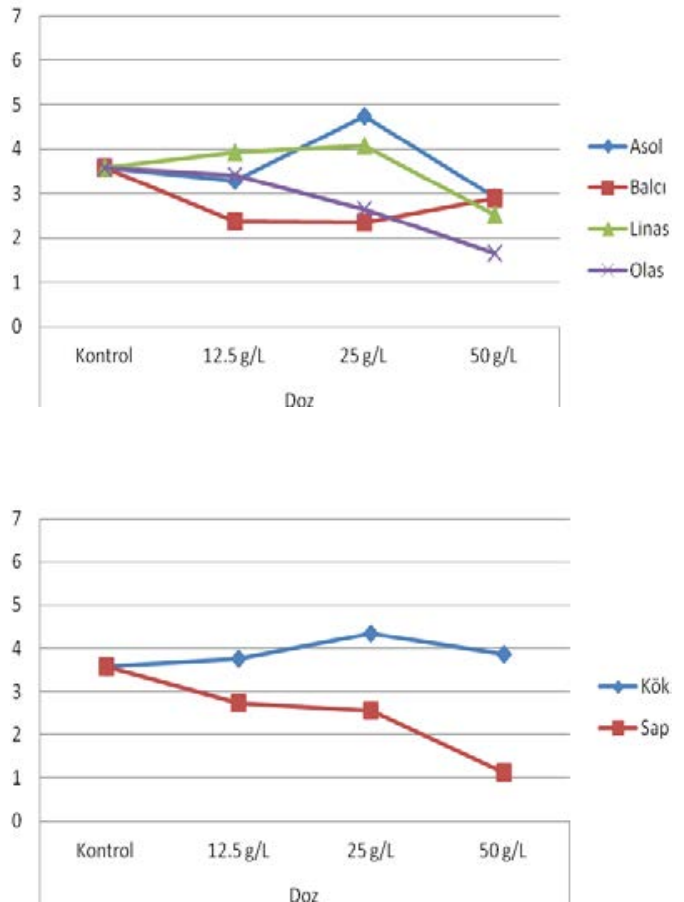

Sürgün uzunluğu $(\mathrm{cm})$
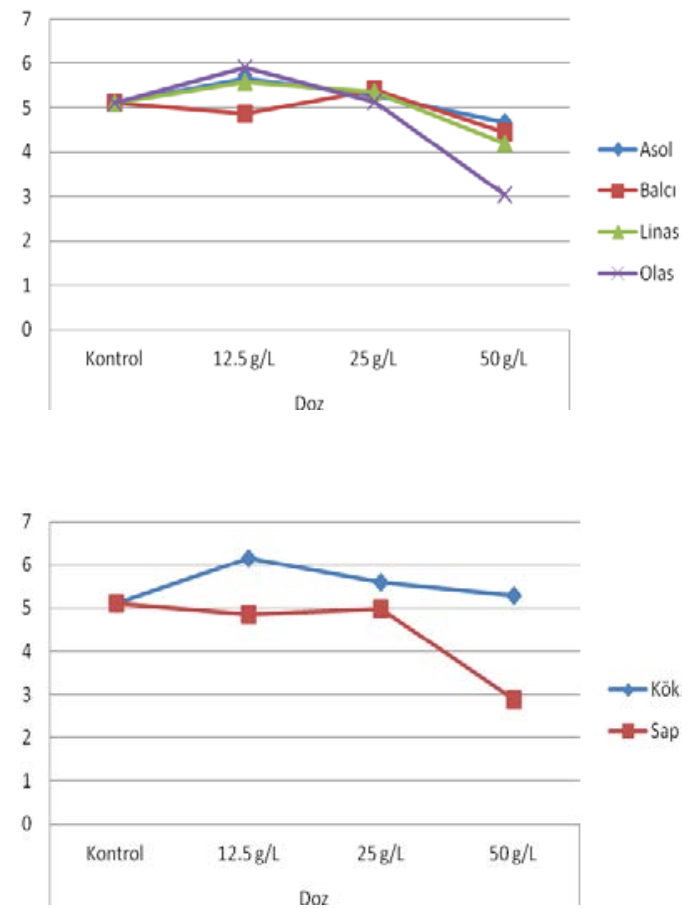

Şekil 3. Aspir bitkisinin kök ve sürgün uzunluğu üzerine çeşit $\times$ doz ve bitki kısımları $\times$ doz interaksiyonları.

\section{Sonuç}

Aspir, köklerinin toprağın derin katmanlarına inebilmesi ile toprağın farklı katmanlarındaki su ve besin maddelerinden yararlanabilmesi nedeniyle kurağa toleransı yüksek olan önemli bir yağ bitkisidir. Bu özelliği ile ülkemizin İç Anadolu Bölgesinde kurak ve yarı kurak alanlarında buğday ve arpa ile ekim nöbetinde yer alabilecek potansiyele sahip bir bitki olarak görülmektedir. Bununla birlikte, buğday-aspir, arpa-aspir ve aspir-aspir ekim nöbeti sistemleri içerisinde aspirin kendisinden sonra gelecek bitkiler üzerine etkilerinin belirlenmesi gerekmektedir.

Bu çalışmada, aspir bitkisinin hasattan sonra tarlada kalan sapları ve köklerinin buğday ve arpa üzerine allelopatik etkileri ile ototoksik etkisini belirlenmek amaçlanmıştır. Araştırma sonucunda, aspir saplarının buğday ve arpanın fide gelişimine, özellikle kök uzaması üzerine allelopatik etkilerinin bulunduğu, aspir köklerinin ise allelopatiye neden olmadığı belirlenmiştir. Özellikle çalışmamızda aspir saplarının EC değerlerinin daha yüksek, $\mathrm{pH}$ değerlerinin de daha düşük olmasının, aspirde allelopatiye neden olan etkenler arasında bu özelliklerin de değerlendirilebileceğini göstermektedir. Benzer bulgular ayçiçeğinde Kaya ve ark. (2013) tarafından da tespit edilmiştir. Bununla birlikte, aspir saplarında bulunan bazı uçucu maddelerin de allelopatik etkiye neden olduğu Day (2016) tarafindan belirlenmiştir. Aspir tohumlarının çimlenmesi ve fide gelişimi de aspir sap solüsyonlarından olumsuz etkilendiği için aspirin ototoksik etkiye de sahip olduğu söylenebilir. Ayrıca, aspir çeşitleri arasında da allelopatik etkiler bakımından farklılıklar olduğu, Asol ve Linas çeşitlerinin buğday ve arpanın çimlenme ve fide gelişimi üzerine olumsuz etkilerinin daha az olduğu sonucuna varılmıştır. Bu nedenle aspir ıslah çalışmalarında genotiplerin bu özelliklerinin de göz önüne alınması ve aspir tarımında çeşit seçiminin sadece verim, yağ oranı ve yağ kalitesi bakımından değerlendirilmemesi gerektiği önerilebilir. Ayrıca, aspir hasadının mümkün olduğunca toprağa yakın yapılarak saplarının tarladan uzaklaştırılması, allelopatik etkilerinin azaltılması bakımından etkili olabileceği söylenebilir. 


\section{Kaynakça}

Bonamigo, T., Fortes, A. M. T., Pinto, T. T., Gomes, F. M., Silva, J. D., \& Buturi, C. V. (2013). Allelopathic interference of safflower leaves with oilseed species. Biotemas, 26(2), 1-8.

Day, S. (2016). Impact of essential oils obtained from safflower stem and roots on germination and seedling growth of wheat, barley, sunflower and chickpea. Turkish Journal of Agriculture-Food Science and Technology, 4(8), 706-711.

Düzgüneş, O., Kesici, T., Kavuncu, O., \& Gürbüz, F. (1987). Araştırma ve Deneme Metodları (İstatistik Metodları II). Ankara Üniversitesi Ziraat Fakültesi Yayınları:1021. Ders Kitab1, s.295.

Far, M. H., \& Bagherzadeh, A. (2018). Assessing allelopathic index for estimating allelopathic potential of Ajowan extracts. Journal of Crop Science and Biotechnology, 21(2), 165-172.

Gülsoy, S., Özkan, K., Mert, A., \& Eser, Y. (2008). Chemical compounds of volatile oil obtained from fruit of Crimean Juniper (Juniperus excelsa) and leaves of Turkish plateau oregano (Origanum minutiflorum) and allelopathic effects on germination of Anatolian Black Pine (Pinus nigra subsp. pallasiana). Journal of Biological Diversity and Conservation, 1(2), 105-114.

Hussain, M. I. \& Reigosa, M. J. (2011). Allelochemical stress inhibits growth, leaf water relations, PSII photochemistry, non-photochemical fluorescence quenching, and heat energy dissipation in three $\mathrm{C}_{3}$ perennial species. Journal of Experimental Botany, 62(13), 4533-4545.

ISTA. (2003). International Seed Testing Association, ISTA Handbook on Seedling Evaluation, 3rd ed.

Işık, D., Mennan, H., Cam, M., Tursun, N., \& Arslan, M. (2016). Allelopathic potential of some essential oil bearing plant extracts on Common Lambsquarters (Chenopodium album L.). Revista De Chimie.(Bucharest), 67(3), 455-459.

Kaya, M. D., Ozcan, F., Day, S., Bayramin, S., \& Ipek, A. (2013). Allellopathic role of essential oils in sunflower stubble on germination and seedling growth of the subsequent crop. International Journal of Agriculture and Biology, 15, 337-341.

Li, Z. H., Wang, Q., Ruan, X., Pan, C. D., \& Jiang, D. A. (2010). Phenolics and plant allelopathy. Molecules, 15(12), 8933-8952.

Miri, H. R. (2011). Allelopathic potential of various plant species on Hordeum spontaneum. Advances in Environmental Biology, 3543-3550.

Modhej, A., Rafatjoo, A., \& Behdarvandi, B. (2013). Allelopathic inhibitory potential of some crop species (wheat, barley, canola, and safflower) and wild mustard (Sinapis arvensis). International Journal of Biosciences, 3(10), 212-220.

Motamedi, M., Karimmojeni, H., \& Sini, F. G. (2016). Evaluation of allelopathic potential of safflower genotypes (Carthamus tinctorius L.). Journal of Plant Protection Research, 56(4), 364-371.

Rice, E. L. (1979). Allelopathy-an update. The Botanical Review, 45(1), 15-109.

Shah, A. N., Iqbal, J., Ullah, A., Yang, G., Yousaf, M., Fahad, S., Tanveer, M., Hassan, W., Tung, S. A., Wang, L., Khan, A., \& Wu, Y. (2016). Allelopathic potential of oil seed crops in production of crops: a review. Environmental Science and Pollution Research, 23(15), 14854-14867

Soltys, D., Krasuska, U., Bogatek, R., \& Gniazdowska, A. (2013). Allelochemicals as bioherbicidespresent and perspectives. In Herbicides-Current research and case studies in use. IntechOpen.

Yurttaş Kılınç, C. (2015). Bazı allelopatik bitki özütlerinin farklı yabancı ot tohumlarının çimlenmesi üzerine etkisi. (Doktora Tezi), Selçuk Üniversitesi Fen Bilimleri Enstitüsü, 60sayfa, Konya, Türkiye.

Willis R. J. (2004). Justus Ludewig von Uslar, and the first book on allelopathy. Dordrecht, The Netherlands: Springer Publications. 